\title{
Editorial
}

\section{The 7th Leonard Berg Symposium, Part 2}

\author{
Gabrielle Strobel \\ Alzheimer Research Forum
}

\section{Cognition Pre-dementia - Like eFAD, Like LOAD?}

At the 7th Leonard Berg Symposium, scientists and patient advocates came together to exchange the latest news on detecting disease presymptomatically and to compare what's known in rare genetic and in common forms of the disease. There was a palpable sense of excitement in the auditorium that, overall, enough lines of evidence are coming together to make preclinical detection possible in practice. Paradoxically, perhaps, this optimism arose alongside a general acknowledgment that autosomal-dominant $\mathrm{AD}$ is surprisingly heterogeneous, and that its status as a faithful model for the much larger population of general late-onset $\mathrm{AD}$ is far from cut and dried. Here are some highlights.

Ira Shoulson is a leading neuro-geneticist and clinician for Huntington disease (HD) at the University of Rochester School of Medicine and Dentistry, New York. He led the conference with a keynote on what the HD experience can teach the AD field. In HD, predictive genetic testing has been possible since 1983; hence, scientists in this community have had more time than their colleagues in AD to study the acceptance and psychological effects of such testing, as well as the characteristics of the presymptomatic period of carriers. Even so, research into preclinical HD is arguably less advanced, partly because fewer large-scale studies exist to observe how the natural history of HD unfolds. In $\mathrm{AD}$, early-stage diagnosis is becoming routine, at least at some academic tertiary care centers. There, clinicians try to implement biomarker-enhanced diagnoses of "prodromal" AD [1] or similarly early stages called by a different name (WashU clinicians would call it incipient or very early $\mathrm{AD}$ ), and the amnestic subtype of the MCI clinical categorization system appears largely to capture the same group of people. Increasingly, specialized centers will diagnose people who do not meet criteria for dementia if they have a mild memory complaint and a pathological CSF or brain scan. The rallying call in $\mathrm{AD}$ now is to move the diagnosis back even further, before the first symptoms appear. In contrast, the diagnosis of HD in the past 20 years has moved back only a year or two as clinicians have become more astute at recognizing early clinical signs, Shoulson said, but it is still an entirely clinical diagnosis made much later than he would wish.

In HD, people on average live 40 years of their lives at risk and 20 more years with the illness, though age of onset varies. For each person with HD, five are living at risk for the disease, but no robust biomarker signatures are in place to identify "silent" disease in these people. Scientists do know that certain abnormalities, such as cortical thinning, predate symptomatic $\mathrm{HD}$, as do certain cognitive impairments, but in practice this has not translated into presymptomatic diagnosis and prevention research. To gather more powerful data on the HD preclinical phase, researchers collaborated to launch PHAROS, an observational study that to date has followed nearly 1,000 at-risk, presymptomatic people for five years. One-third of them have the extended glutamine repeat and will develop HD. "We asked people if they would come back every nine months for evaluation. We would not share with them what we found, and we wanted their blood and put it in a database. This was very daunting, particularly securing confidentiality and privacy. It was, in part, what led to the passage of Genetic Information Nondiscrimination Act (GINA)," Shoulson told the audience.

PHAROS appears to have been worth the effort. Its initial data show that all motor and cognitive domains 
monitored indeed reveal abnormalities in carriers compared to their fellow non-carriers. On most tests, the differences grew over time, whereas in some tests they were present from the first assessment and then stayed constant over time. Importantly, however, on each test, the carrier vs. non-carrier curves were separate throughout the duration of the study, showing that carriers already do a little more poorly in those functions that will develop overt symptoms years later. "People carrying expanded repeats did worse at baseline and worsened more over time on both motor and cognitive scores," Shoulson said. This is instructive for DIAN, which will also compare carriers to non-carriers in the decade or so before disease onset. DIAN, however, uses a different panel of assessments more heavily weighted toward imaging and CSF biomarker data. The PHAROS study stored no CSF but did store serum and urine samples; no data are available from the fluids yet. In PHAROS, as in DIAN, the hope is to use the data to identify subsets of people who are within five years prior to their diagnosis and offer targeted drug trials to them.

John Morris then summarized the rationale for DI$\mathrm{AN}$ and added to it the latest data in the WashU group's ongoing studies to define exactly a detectable biological identity of those five years. Scientists have known for a decade that a sizable fraction of aging people have pathological $\mathrm{AD}$ - amyloid plaques and neurofibrillary tangles - without the disease's symptoms [2], and in the past five years, amyloid imaging has vividly confirmed this finding. Many scientists have interpreted this to mean that there likely exists a long, clinically silent stage during which AD pathogenesis operates biochemically and neurobiologically in ways that should be identified for diagnosis and early intervention. "Our efforts since then have been to characterize that stage," Morris said.

The finding that people live with AD pathology but no symptoms also renewed a debate about whether perhaps that pathology is benign. It is absolutely not, Morris said emphatically in St. Louis. In his view, people with this pathology will develop the symptoms of AD. Exactly when that happens in a given person depends on factors such as their brain and cognitive reserve, inflammatory state, vascular health, and perhaps exercise and other environmental factors. Other speakers appeared to agree with this view.

New data to advance this old debate is coming on several fronts, Morris said. For one, an upcoming paper by Martha Storandt and colleagues at WashU found that, even in people who do not meet criteria for dementia, the presence of amyloid in the brain as seen by PIB positron emission tomography (PET) imaging comes with a sharp decline in global composite cognitive performance. For another, a WashU study led by David Johnson (now at the University of Kansas) and James Galvin reported in the October Archives of Neurology a measurable drop in cognitive performance among 444 volunteers during the transition from healthy aging to symptomatic AD [3]. People's performance curves suddenly veered downward three years to one year before they got clinically diagnosed, even though the clinicians at WashU strive to pick up AD early. Notably, visuospatial performance caved in first, suggesting that a sole focus on episodic memory in clinical testing may miss earlier telltale signs. Episodic and working memory declined measurably in the year before diagnosis.

This result echoes studies from a growing group of other investigators who find changes in visuospatial and other domains years before a person becomes impaired enough to receive a clinical diagnosis. For example, at last July's ICAD in Vienna, Jean Francois Dartigues of the University of Bordeaux, France, presented extensive and similar data from PAQUID, a communitybased natural history study in the Bordeaux area that has assessed 3,777 elderly people every other year for 14 years. In Vienna, Dartigues reported that people who were eventually diagnosed with incident dementia by DSM-IV criteria (i.e., years down the road from when they would get diagnosed at WashU) started declining subtly in processing speed, semantic memory, and verbal fluency some 12 years prior to formal diagnosis. Other, broader domains of memory and executive function commonly declined a few years thereafter, all of which preceded depression and the person's own sense that something was wrong [4]. At ICAD, Dartigues detailed declines in multiple cognitive tests preceding an $\mathrm{AD}$ diagnosis that clearly differed from the curves of normally aging people. Both studies imply that studies of normal aging may contain a sizable fraction of people who in fact have preclinical $\mathrm{AD}$, and thus perhaps overestimate the effects of truly healthy aging.

Storandt's, Galvin's, and Dartigues' data comes from prospective work in either self-selected or communitybased elderly people. What about dominantly inherited AD? At the Leonard Berg Symposium, Martin Rossor of University College London, UK, noted that from the very beginning of research with carriers of $\mathrm{A} \beta \mathrm{PP}$ and presenilin mutations, changes in verbal, visual, and spatial memory were found to precede a broader deterioration that signaled the onset of clinical AD [5]. Francisco Lopera is a neurologist at Antioquia University School of Medicine, Medellín, Colombia, who 
works with the world's largest known pedigree carrying a presenilin mutation and attended the Leonard Berg Symposium. His research has pointed to verbal and semantic memory as early indicators, as well. And John Ringman of the University of California, Los Angeles, found stark differences in both the trail making test (which taxes visuospatial and executive speed) and verbal memory tests when he compared 30 mutation carriers and 21 non-carriers from 10 Mexican families with presenilin mutations. These differences between non-carriers and carriers arose with age; they were not evident when carriers were still 20 years away from their family's expected age of onset but were about five years prior [6]. Since then, a newer study of $42 \mathrm{Mexi}-$ can American people at risk of a pathogenic presenilin mutation has begun, and many of these subjects are opting to participate in DIAN, Ringman said. While these tests broadly point to the same functional domains, getting scientists to agree which tests to use will be one of the bigger challenges of any joint prevention initiative, several speakers at the Berg Symposium acknowledged. To name but a few, cued semantic recall tests and attention tests measuring intrusion errors are also increasingly cropping up as sensitive indicators very early on, and cognitive psychologists are known for fiercely debating the pros and cons of their favorite tests.

Based on this and other data, it seems that what scientists have found out about the preclinical cognitive decline in autosomal-dominant familial AD largely jibes with findings from late-onset $\mathrm{AD}$, Rossor and other speakers said. "Cognitive decline in early familial AD is similar to that seen in LOAD," said Ringman. This, in turn, holds out hope that biomarker data from the DIAN network may likewise be generalizable to the common forms of AD. A predictive biomarker signature is indispensable because longitudinal studies are not an option for the diagnosing physician, who ideally needs to get the job done in a single visit.

\section{Biomarkers Pre-dementia - Like eFAD, Like LOAD?}

It is a sign of progress in $\mathrm{AD}$ research that longitudinal observational studies are beginning to converge on when and how a person's cognition shows the first subtle signs of trouble on the way to dementia. That's dandy for research, but clinicians urgently need robust tools to diagnose presymptomatic dementia in one clinic visit. Part of the toolkit for that will come from biomarkers, and at the 7th Leonard Berg Symposium, scientists shared some of the latest news in this burgeoning area of study. As throughout this conference, talks toggled between what's known in LOAD and eFAD, comparing all the while how well knowledge on these forms of $\mathrm{AD}$ matches up.

John Morris of WashU started the topic with an update on his center's Antecedent Biomarker Study, which has been seeking to find a predictive combination of biomarkers in cognitively normal adult children of a parent with AD since 2005. (These are not families with dominantly inherited AD.) Dispensing with cautious qualifiers, Morris summed up the bottom line of this work: "We can detect preclinical AD in cognitively normal older adults." How long before dementia? About four years. And this is how it works, claimed Morris: When people have reduced CSF A $\beta_{42}$, elevated CSF tau/phospho-tau, and amyloid in their brains, they will subsequently develop dementia. Their $\mathrm{A} \beta_{42}$ drops first, brain amyloid shows up soon after, and tau starts rising just prior to symptoms (for comparison, see Johnson diagram below). Almost all people whose CSF $\mathrm{A} \beta_{42}$ is abnormally low also have amyloid in their brains.

This website has covered many individual studies on the way to this conclusion [7-12], as well as the broader literature showing that damage to the brain is extensive by the time a person is diagnosed. Hence, this story will focus on the latest data presented in St. Louis. For example, Morris reported that the amyloid in people's brains is driven by the two leading risk factors for lateonset $\mathrm{AD}$ - age and apolipoprotein E (ApoE). In a PIB PET series of 241 cognitively normal people age 45 to 89 , brain amyloid started showing up around age 55 and became more and more frequent in older folks [13]. People with ApoE4 were highly overrepresented relative to their allele frequency among the PIB-positive group, whereas almost no one with ApoE2 had brain amyloid even up into the highest ages. In the sixties, seventies, and eighties, the percentages of people with ApoE4 being positive for PIB were 37, 53, and 75, respectively; for people without ApoE4, these numbers were 8,16 , and 16 percent by comparison. "This suggests that expression of the E4 phenotype is very strongly associated with presence of cerebral $\mathrm{A} \beta$ deposits as people age," Morris said. In essence, this makes brain amyloid a phenotype of sorts of ApoE4 [14], and having amyloid in the brain predicts that the person would develop AD symptoms when followed for up to 5.5 years (mean of 2.4 years) [13].

Besides ApoE and age, scientists are currently looking to relate the two linked biomarkers of abnormal 
CSF/brain amyloid to additional known risk factors and markers of AD. The hope is that a comprehensive picture might emerge of how multiple parts of the biology fit together in the preclinical phase. One recent step in this effort was a paper showing that in cognitively normal people, the abnormal CSF signature is statistically linked with brain atrophy; at later stages, when dementia sets in, tau drives the CSF-atrophy relationship as it continues to rise while the brain continues to shrink with progressing illness [15]. More than just whole brain atrophy, brain amyloid in cognitively normal older adults is associated with thinning of the cortex in regions known to be vulnerable to AD pathology [16]. This suggests that a preclinical CSF signature is beginning to match up with an imaging signature composed of amyloid and cortical thinning.

In his talk, David Holtzman of WashU noted that a new Dutch/MGH study reporting reduced CSF A $\beta_{40}$ concentrations in cerebral amyloid angiopathy (CAA) provided yet another independent confirmation for the general idea that as amyloid deposits in the brain, in this case on blood vessels, it becomes trapped and $\mathrm{A} \beta$ concentrations in the CSF drop. CAA is a common cause of strokes [17].

An upcoming paper from the WashU group further tightens the connection between brain amyloid and CSF $\mathrm{A} \beta$ by analyzing CSF $\mathrm{A} \beta$ versus PIB and age in 189 cognitively normal people, Holtzman said [18]. In this series, everyone whose brain binds PIB also has low CSF A $\beta_{42}$, but the opposite is not true. Some people, especially the youngest participants between 45 and 55 years of age, already have low CSF $\mathrm{A} \beta_{42}$ but no PIB. The scientists interpret this to mean that brain amyloid deposition begins in a conformation that may initially be invisible to PIB. The subsequent drop in CSF A $\beta_{42}$ would consequently be the earliest detectable biomarker at present. When the brain amyloid later becomes fibrillar, it binds PIB. "This is our impression so far, but we do not have proof yet," said Holtzman. "We have to follow these cohorts longer to see in which order these markers come up."

The same paper also contains more data connecting the CSF combination of high tau/low $\mathrm{A} \beta_{42}$ with brain amyloid, in essence predicting that this CSF signature reflects ongoing neurodegeneration and will predict onset of symptoms in the next three to five years. Building on a smaller previous study, this finding extends into cognitively normal people in a widely cited study from Kaj Blennow's group three years ago, in which virtually everyone with this CSF signature among a large cohort of MCI patients converted to $\mathrm{AD}$ within five years [19]. In this study and an independent recent one, these biomarkers predicted not only whether people would develop $\mathrm{AD}$, but also how fast their cognitive decline would progress [20].

Now, for the first time, a pharma company, BristolMyers Squibb, targets people at this pre-dementia stage for a drug trial. The new twist, compared to previous MCI trials (which all failed), is that not an MCI diagnosis but a low CSF A $\beta_{42}$ level plus a subjective memory complaint determine whether a person can enter the trial. CSF A $\beta /$ tau and brain atrophy are the outcome measures listed just below safety. If the distinction between CSF $\mathrm{A} \beta_{42}$ and CSF tau changes holds up in larger studies, i.e., if the former truly precedes the latter by two years or so, then future trials could push back to treating asymptomatic people by screening for low CSF $\mathrm{A} \beta_{42}$ and enrolling people just at the point when their tau is beginning to nudge up but before they have symptoms. CSF tau could then conceivably become an outcome measure to see if the drug is effective. That, then, would constitute a prevention trial, and it may soon come within reach, said Reisa Sperling of Brigham and Women's Hospital.

These data come from research with volunteers who have, or may develop, the common forms of AD. Establishing the order of antecedent biomarkers in dominantly inherited (aka autosomal-dominant or earlyonset familial) AD with sufficient statistical power to support drug trials is part of what DIAN is aiming to accomplish. Small biomarker studies with individual families have already begun to pave the way. For example, researchers led by Dan Pollen of University of Massachusetts Medical Center in Worcester, who described the first reported presenilin 1 family, reported $\mathrm{CSF} \mathrm{A} \beta_{42}$ decreases in six presymptomatic mutation carriers [21]. Last year, John Ringman of UCLA reported the same thing, plus that CSF tau was increased. In this study, CSF isoprostanes were up, too, as was plasma $\mathrm{A} \beta$ [22].

At the Leonard Berg Symposium, Raquel SanchezValle of the Hospital Clinic in Barcelona, Spain, reported new CSF and plasma data on 14 relatives from four different families with presenilin mutations. Of the eight participants who carried the AD mutation, half were symptomatic, half not yet. These Spanish investigators offer genetic counseling, testing, and observational research to families with genetic neurodegenerative diseases including eFAD. Sanchez-Valle presented the first cross-sectional data of what is to become a longitudinal study of these volunteers. Using Innogenetics' Innotest for CSF, and a cutoff value of 
$495 \mathrm{pg} / \mathrm{ml}$ [23], CSF A $\beta_{42}$ levels were normal, i.e., high, in those presymptomatic carriers who were still more than a decade away from their family's mean age at onset, and low in even mildly symptomatic carriers, Sanchez-Valle reported. CSF tau was elevated only by the time carriers became clearly symptomatic, and it then correlated strongly with a person's clinical dementia rating or the Mini-Mental Status Examination (MMSE). This Spanish group found no differences in amyloid plasma between carriers and non-carriers in this initial study.

"Overall, this indicates that the same kind of changes are occurring in dominantly inherited $\mathrm{AD}$ as in lateonset AD," Holtzman said, but cautioned that these studies are all very small.

That said, speakers in St. Louis agreed that neither DIAN, nor ADNI), nor the Adult Children Study and other cohorts should restrict their analyses to the usual suspects $\mathrm{A} \beta$ and tau. A multitude of other markers are coming out of proteomics analyses of CSF and plasma, and some bear close watching. For example, Eric Portelius, working with Henrik Zetterberg and Kaj Blennow at University of Gothenberg in Sweden, has developed combined immunoprecipitation/MALDI-TOF mass spec protocols to explore the proteomic diversity of $\mathrm{A} \beta$ and $\mathrm{A} \beta \mathrm{PP}$ species in CSF of LOAD and FAD. The Swedish scientists have found some 20 different $\mathrm{A} \beta$ species in CSF; $\mathrm{A} \beta_{42}$ was one of the least abundant ones. It is important to disease because it is hydrophobic and aggregates readily, but as biomarkers, other species may be easier to use and more informative. Variability among centers, particularly in $\mathrm{A} \beta_{42}$ measurements, has been dogging the field for some time [24,25]. At ICAD in Vienna, Zetterberg included in his plenary lecture unpublished data suggesting that in the CSF of some familial AD cases, $\mathrm{A} \beta_{37}, \mathrm{~A} \beta_{38}$, and $\mathrm{A} \beta_{39}$ were all particularly low, whereas an $\mathrm{A} \beta_{1-16}$ fragment was abnormally high. This pattern differed starkly between PS-mutant AD and sporadic $\mathrm{AD}$, though both forms had similar, and expected, findings on $\mathrm{A} \beta_{40}$ and $\mathrm{A} \beta_{42}$. $\mathrm{A} \beta_{1-16}$ popped out of that work as a novel biomarker candidate for both sporadic and familial AD. "DIAN should look at these other species, too," Holtzman said.

Also at ICAD, Zetterberg presented his group's detection in CSF of AD patients of a set of truncated $\mathrm{A} \beta$ forms, as well as a set of $\mathrm{A} \beta \mathrm{PP}$ fragments, both of which point to the existence of a new, yet-to-bedefined cleavage sequence of A $\beta$ PP [26-28]. Beyond $\mathrm{A} \beta \mathrm{PP}$ and $\mathrm{A} \beta$ species, a wealth of potential markers are being discovered. To quote but one example from the
Leonard Berg Symposium, the poster session featured a study by Rawan Tarawneh and colleagues at WashU on the neuronal injury marker VILIP-1, an intracellular calcium-sensor that tracked with dementia severity in a small study of nine AD patients and 15 controls.

\section{REFERENCES}

[1] Dubois B, Feldman HH, Jacova C, Dekosky ST, BarbergerGateau P, Cummings J, Delacourte A, Galasko D, Gauthier S, Jicha G, Meguro K, O'brien J, Pasquier F, Robert P, Rossor M, Salloway S, Stern Y, Visser PJ, Scheltens P (2007) Research criteria for the diagnosis of Alzheimer's disease: revising the NINCDS-ADRDA criteria. Lancet Neurol 6, 734-746.

[2] Price JL, Morris JC (1999) Tangles and plaques in nondemented aging and preclinical Alzheimer's disease. Ann Neurol 45, 358-368.

[3] Johnson DK, Storandt M, Morris JC, Galvin JE (2009) Longitudinal study of the transition from healthy aging to Alzheimer disease. Arch Neurol 66, 1254-1259.

[4] Amieva H, Le Goff M, Millet X, Orgogozo JM, Pérès K, Barberger-Gateau P, Jacqmin-Gadda H, Dartigues JF (2008) Prodromal Alzheimer's disease: successive emergence of the clinical symptoms. Ann Neurol 64, 492-498.

[5] Newman SK, Warrington EK, Kennedy AM, Rossor MN (1994) The earliest cognitive change in a person with familial Alzheimer's disease: presymptomatic neuropsychological features in a pedigree with familial Alzheimer's disease confirmed at necropsy. J Neurol Neurosurg Psychiatry 57, 967972.

[6] Ringman JM, Diaz-Olavarrieta C, Rodriguez Y, Chavez M, Fairbanks L, Paz F, Varpetian A, Maldonado HC, Macias-Islas MA, Murrell J, Ghetti B, Kawas C (2005) Neuropsychological function in nondemented carriers of presenilin-1 mutations. Neurology 65, 552-558.

[7] Skoog I, Davidsson P, Aevarsson O, Vanderstichele H, Vanmechelen E, Blennow K (2003) Cerebrospinal fluid betaamyloid 42 is reduced before the onset of sporadic dementia: a population-based study in 85-year-olds. Dement Geriatr Cogn Disord 15, 169-176.

[8] Sunderland T, Linker G, Mirza N, Putnam KT, Friedman DL, Kimmel LH, Bergeson J, Manetti GJ, Zimmermann M, Tang B, Bartko JJ, Cohen RM (2003) Decreased beta-amyloid1-42 and increased tau levels in cerebrospinal fluid of patients with Alzheimer disease. JAMA 289, 2094-2103.

[9] Fagan AM, Mintun MA, Mach RH, Lee SY, Dence CS, Shah AR, Larossa GN, Spinner ML, Klunk WE, Mathis CA, Dekosky ST, Morris JC, Holtzman DM (2006) Inverse relation between in vivo amyloid imaging load and cerebrospinal fluid Abeta42 in humans. Ann Neurol 59, 512-519.

[10] Fagan AM, Roe CM, Xiong C, Mintun MA, Morris JC, Holtzman DM (2007) Cerebrospinal fluid tau/beta-amyloid(42) ratio as a prediction of cognitive decline in nondemented older adults. Arch Neurol 64, 343-349.

[11] Li G, Sokal I, Quinn JF, Leverenz JB, Brodey M, Schellenberg GD, Kaye JA, Raskind MA, Zhang J, Peskind ER, Montine TJ (2007) CSF tau/Abeta42 ratio for increased risk of mild cognitive impairment: a follow-up study. Neurology 69, 631639.

[12] Shaw LM, Vanderstichele H, Knapik-Czajka M, Clark CM, Aisen PS, Petersen RC, Blennow K, Soares H, Simon A, 
Lewczuk P, Dean R, Siemers E, Potter W, Lee VM, Trojanowski JQ, Alzheimer's Disease Neuroimaging Initiative (2009) Cerebrospinal fluid biomarker signature in Alzheimer's disease neuroimaging initiative subjects. Ann Neurol 65, 403413.

[13] Morris JC, Roe CM, Grant EA, Head D, Storandt M, Goate AM, Fagan AM, Holtzman DM, Mintun MA (2009) Pittsburgh compound $\mathrm{B}$ imaging and prediction of progression from cognitive normality to symptomatic Alzheimer disease. Arch Neurol 66, 1469-1475.

[14] Reiman EM, Chen K, Liu X, Bandy D, Yu M, Lee W, Ayutyanont N, Keppler J, Reeder SA, Langbaum JB, Alexander GE, Klunk WE, Mathis CA, Price JC, Aizenstein HJ, DeKosky ST, Caselli RJ (2009) Fibrillar amyloid-beta burden in cognitively normal people at 3 levels of genetic risk for Alzheimer's disease. Proc Natl Acad Sci U S A 106, 68206825.

[15] Fagan AM, Head D, Shah AR, Marcus D, Mintun M, Morris JC, Holtzman DM (2009) Decreased cerebrospinal fluid $\operatorname{Abeta}(42)$ correlates with brain atrophy in cognitively normal elderly. Ann Neurol 65, 176-183.

[16] Dickerson BC, Bakkour A, Salat DH, Feczko E, Pacheco J, Greve DN, Grodstein F, Wright CI, Blacker D, Rosas HD, Sperling RA, Atri A, Growdon JH, Hyman BT, Morris JC, Fischl B, Buckner RL (2009) The cortical signature of Alzheimer's disease: regionally specific cortical thinning relates to symptom severity in very mild to mild $\mathrm{AD}$ dementia and is detectable in asymptomatic amyloid-positive individuals. Cereb Cortex 19, 497-510.

[17] Verbeek MM, Kremer BP, Rikkert MO, Van Domburg PH, Skehan ME, Greenberg SM (2009) Cerebrospinal fluid amyloid beta(40) is decreased in cerebral amyloid angiopathy. Ann Neurol 66, 245-249.

[18] Fagan AM, Mintun MA, Shah AR, Aldea P, Roe CM, Mach RH, Marcus D, Morris JC, Holtzman DM (2009) Cerebrospinal fluid tau and ptau181 increase with cortical amyloid deposition in cognitively normal individuals: Implications for future clinical trials of Alzheimer's disease. EMBO Mol Med 1,371-380.

[19] Hansson O, Zetterberg H, Buchhave P, Londos E, Blennow K, Minthon L (2006) Association between CSF biomarkers and incipient Alzheimer's disease in patients with mild cognitive impairment: a follow-up study. Lancet Neurol 5, 228-234.

[20] Snider BJ, Fagan AM, Roe C, Shah AR, Grant EA, Xiong C,
Morris JC, Holtzman DM (2009) Cerebrospinal fluid biomarkers and rate of cognitive decline in very mild dementia of the Alzheimer type. Arch Neurol 66, 638-645.

[21] Moonis M, Swearer JM, Dayaw MP, St George-Hyslop P, Rogaeva E, Kawarai T, Pollen DA (2005) Familial Alzheimer disease: decreases in CSF Abeta42 levels precede cognitive decline. Neurology 65, 323-325.

[22] Ringman JM, Younkin SG, Pratico D, Seltzer W, Cole GM Geschwind DH, Rodriguez-Agudelo Y, Schaffer B, Fein J, Sokolow S, Rosario ER, Gylys KH, Varpetian A, Medina LD, Cummings JL (2008) Biochemical markers in persons with preclinical familial Alzheimer disease. Neurology 71, 85-92.

[23] van der Vlies AE, Verwey NA, Bouwman FH, Blankenstein MA, Klein M, Scheltens P, van der Flier WM (2009) CSF biomarkers in relationship to cognitive profiles in Alzheimer disease. Neurology 72, 1056-1061.

[24] Verwey NA, van der Flier WM, Blennow K, Clark C, Sokolow S, De Deyn PP, Galasko D, Hampel H, Hartmann T, Kapaki E, Lannfelt L, Mehta PD, Parnetti L, Petzold A, Pirttila T, Saleh L, Skinningsrud A, Swieten JC, Verbeek MM, Wiltfang J, Younkin S, Scheltens P, Blankenstein MA (2009) A worldwide multicentre comparison of assays for cerebrospinal fluid biomarkers in Alzheimer's disease. Ann Clin Biochem 46(Pt 3), 235-240.

[25] Mattsson N, Zetterberg H, Hansson O, Andreasen N, Parnetti L, Jonsson M, Herukka SK, van der Flier WM, Blankenstein MA, Ewers M, Rich K, Kaiser E, Verbeek M, Tsolaki M, Mulugeta E, Rosén E, Aarsland D, Visser PJ, Schröder J, Marcusson J, de Leon M, Hampel H, Scheltens P, Pirttilä T, Wallin A, Jönhagen ME, Minthon L, Winblad B, Blennow K (2009) CSF biomarkers and incipient Alzheimer disease in patients with mild cognitive impairment. JAMA 302, 385-393.

[26] Portelius E, Brinkmalm G, Tran AJ, Zetterberg H, WestmanBrinkmalm A, Blennow K (2009) Identification of novel APP/Abeta isoforms in human cerebrospinal fluid. Neurodegener Dis 6, 87-94.

[27] Portelius E, Brinkmalm G, Tran A, Andreasson U, Zetterberg H, Westman-Brinkmalm A, Blennow K, Ohrfelt A (2009) Identification of novel N-terminal fragments of amyloid precursor protein in cerebrospinal fluid. Exp Neurol, in press.

[28] Portelius E, Price E, Brinkmalm G, Stiteler M, Olsson M, Persson R, Westman-Brinkmalm A, Zetterberg H, Simon AJ, Blennow K (2009) A novel pathway for amyloid precursor protein processing. Neurobiol Aging, in press. 